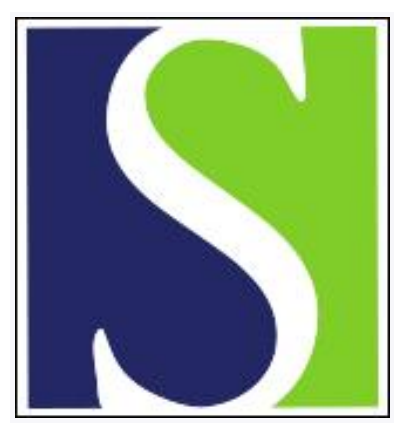

Scand J Work Environ Health 2000;26(5):398-405

https://doi.org/10.5271/sjweh.560

Issue date: Oct 2000

Measuring and characterizing force exposure during computer mouse use

by Johnson PW, Hagberg M, Wigaeus Hjelm E, Rempel D

The following articles refer to this text: SJWEH Supplements 2007;(3):26-32; 2009;35(2):85-95; 2013;39(4):379-389

Key terms: computer work; exposure assessment; force; upper extremity

This article in PubMed: www.ncbi.nlm.nih.gov/pubmed/11103838

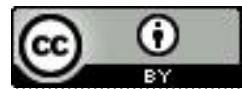




\title{
Measuring and characterizing force exposures during computer mouse use
}

\author{
by Peter W Johnson, PhD, ,2,3 Mats Hagberg, MD, 'Ewa Wigaeus Hjelm, PhD, ${ }^{2}$ David Rempel, MD
}

\begin{abstract}
Johnson PW, Hagberg M, Wigaeus Hjelm E, Rempel D. Measuring and characterizing force exposures during computer mouse use. Scand J Work Environ Health 2000;26(5):398-405.

Objectives The purpose of this study was to develop and validate a sampling strategy for characterizing the finger force exposures associated with computer mouse use.

Methods Mouse forces were measured from 16 subjects ( 8 men, 8 women), on 3 separate days, at their actual workstations while they performed (i) their regular work, (ii) a battery of standardized tasks, and (iii) simulated mouse use.

Results The forces applied to the mouse did not vary between hours or days. During regular work, the mouse was used 78.0 (SD 40.7) times per hour, accounting for 23.7 (SD 9.5)\% of the worktime. The mean forces applied to the sides and button of the mouse were low, averaging $0.6 \%(0.35 \mathrm{~N})$ and $0.8 \%(0.43 \mathrm{~N})$ of the maximal voluntary contraction, respectively. The forces applied to the mouse during the standardized tasks differed from the regular work forces; however, there were moderate-to-strong correlations between the 2 measures.

Conclusions With respect to performing exposure assessment studies, the 3 major findings were (i) mouse force measurements should be made while subjects perform their actual work in order to characterize the absolute applied force accurately, (ii) the forces applied to the mouse during the performance of a short battery of standardized tasks can be used to characterize relative exposure and identify computer operators or work situations for which higher forces are applied to the mouse, and (iii) subjects cannot accurately simulate mouse forces.
\end{abstract}

Key terms computer work, exposure assessment, force, upper extremities.

Recent studies have shown that musculoskeletal disorders may be associated with the use of the computer mouse $(1-3)$ and that these apparent mouse-related disorders are increasing (4). Before the relationship between mouse use and disorders in the mouse-using arm can be understood, mouse use patterns (ie, the amount and type of mouse use) and the biomechanical components of mouse operation (force, repetition, posture, muscle loading patterns, etc) must be assessed.

The amount of mouse use and the forces applied to the mouse by a computer operator are 2 risk factors that may play an important role in the development of musculoskeletal disorders (5). A limited number of studies has attempted to characterize the physical "doses" associated with mouse use $(6,7)$ and the physiological "responses" as a result of mouse operation (8-14). However, these studies were all small-scale laboratory investigations. Exposure assessment of computer mouse use in larger scale, real work settings is needed to help clarify the role that the various risk factors play in the development of mouse-related musculoskeletal disorders. Currently, it is uncertain what the exposures to the various mouse-related risk factors are and how the exposures vary between persons, occupations, computer systems, and software applications.

One of our long-term goals is to develop and validate a sampling strategy suitable for use in epidemiologic studies in order to determine whether there is any predictive value between the forces computer operators apply to their mouse and the development of upper-extremity musculoskeletal disorders. In order to achieve our long-term goals, the primary aims of this study were to (i) characterize mouse use and force exposures among a group of computer operators while they performed their usual work at their workstations, (ii) compare differences in computer mouse use between male and female

1 Department of Occupational Medicine, Sahlgrenska University Hospital, Göteborg, Sweden.

2 Department for Work and Health, National Institute for Working Life, Solna, Sweden.

3 Division of Occupational and Environmental Medicine, University of California, San Francisco, California, United States.

Reprint requests to: Dr Mats Hagberg, Department of Occupational Medicine, Sahlgrenska University Hospital, St Sigfridsga$\tan$ 85, 41266 Göteborg, Sweden. [E-mail: mats.hagberg@ymk.gu.se] 
operators, and (iii) develop and validate an exposure assessment sampling strategy to characterize accurately the forces computer operators apply to the mouse.

A secondary aim of this study was to determine whether simpler and quicker methods, other than making time-consuming "real work" measurements of force, can be used to characterize a computer mouse operator's level of force exposure. Therefore, the forces applied to the mouse were measured while subjects performed a battery of standardized tasks, and forces were also measured while subjects simply tried to simulate mouse use.

\section{Subjects and methods}

\section{Subjects}

Sixteen experienced Macintosh computer users ( $8 \mathrm{men}$, 8 women) with a mean age of 41.6 (SD 6.1) years participated in the study. All the subjects were full-time employees at the National Institute for Working Life in Solna, Sweden. The subjects were administrative personnel $(\mathrm{N}=3)$, support staff $(\mathrm{N}=3)$, computer administrators $(\mathrm{N}=2)$, and researcher staff $(\mathrm{N}=8)$.

The subjects were asked to participate in the study during days in which they planned to use their computer (ie, not in meetings or away from the worksite for part of the day). The experiment consisted of (i) continuously measuring the forces the subjects applied to the mouse while they performed their regular work, (ii) measuring the forces applied to the mouse while the subjects performed a battery of standardized tasks, and (iii) measuring the forces the subjects applied to the mouse while they tried to simulate mouse use.

\section{Force measurements during regular work}

A force-sensing Apple ADBII mouse was used to measure the forces the subjects applied to the sides and button of the mouse while they performed their work. The force-sensing mouse was fully operational and similar in weight, feel, and appearance to their regular Apple ADBII mouse. The design and measurement accuracy of the force-sensing mouse has been validated, described, and discussed in detail elsewhere $(15,16)$.

The mouse force measurements took place at the subject's actual workstation while they performed their regular work. Data acquisition equipment, consisting of the instrumented mouse (Ergonomics Program, University of California - San Francisco, Richmond, CA, USA), a 2channel portable amplifier (model 1210, FFA; Bromma, Sweden) and a portable computer (Lap Power AB; Stockholm, Sweden) were set up in the subject's office. After a short briefing, the data acquisition equipment was turned on, and the subject was left alone to perform his or her regular work.
Continuous force measurements were collected from each subject on 3 separate days with an average of 20 days between each measurement. On 1 day, force measurements were collected over the full workday with the data collection periods broken into 61 -hour blocks. On 2 other days the data were collected in 1-hour increments for either a half or full workday ( 3 or 6 hours). The force signals from the instrumented mouse were sampled at 20 or $60 \mathrm{~Hz}$. The calibration of the force-sensing mouse was verified at the beginning and end of each day by applying known forces $(0.3,0.6,1.0,4.0 \mathrm{~N})$ to the sides and button of the mouse.

\section{Force measurements during standardized tasks}

Each subject's regular work was periodically interrupted so that a battery of standardized tasks could be performed. The standardized task battery was performed once every hour on the 1st day (6 times) and at the beginning and end of the day on the 2 nd and 3rd days ( 2 times). The order of the standardized task battery was randomized; the battery included the following 3 tasks: (i) an omnidirectional pointing task designed to simulate moving and clicking on objects with the mouse, (ii) an omnidirectional dragging task designed to simulate moving and manipulating objects with the mouse, and (iii) a text-editing task designed to simulate text editing during the use of word-processing applications. On the 1st day, before the experiment started, the subjects were allowed to familiarize themselves with the standardized tasks by performing each of them once. They were instructed to perform the standardized tasks at their own pace, and no time constraints were imposed. Force data during the performance of the standardized tasks were collected at $60 \mathrm{~Hz}$.

The omnidirectional pointing task consisted of alternately clicking on 18 evenly spaced $1.2-\mathrm{cm}$ circular targets, arranged in a large circle and spaced $7.5 \mathrm{~cm}$ apart (figure 1). Each target first turned black to indicate that it was active; then the subject clicked on the target with their mouse and it disappeared. This sequence continued until all 18 targets had been acquired. The omnidirectional dragging task consisted of dragging 9 evenly spaced $1.2-\mathrm{cm}$ circular targets to 9 diametrically opposite destination targets $(1.2-\mathrm{cm}$ circles $)$ spaced $7.5 \mathrm{~cm}$ apart (figure 2). First, the active and destination targets turned black and grey, respectively. Then the active target was acquired and dragged to the destination target and released, and both targets disappeared. This procedure continued until all 9 targets were dragged to their respective destinations.

There were 4 paragraphs, 5 lines long, of 12-point Courier text in the text-editing task. In each line, at a random location, 1 to 4 characters were highlighted using bold text. The subjects were instructed to select the bold text with the mouse, and then delete the text by hitting 


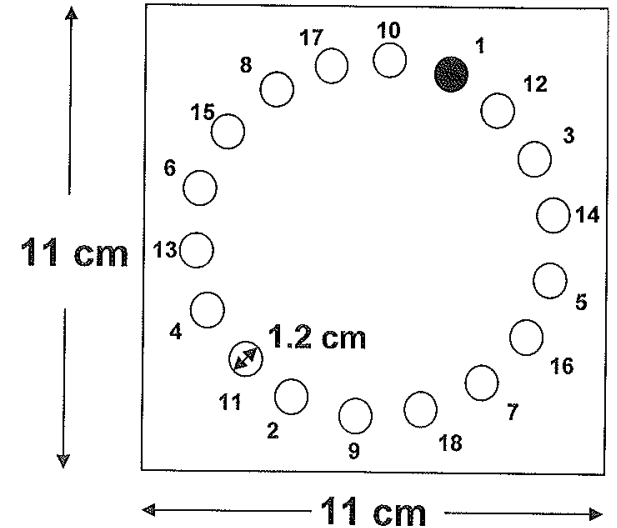

Figure 1. Omnidirectional pointing task and screen dimensions of targets. The numbers next to the circles represent the sequence of the tasks. After a participant clicks on target 1 , target 2 turns black, and so forth.

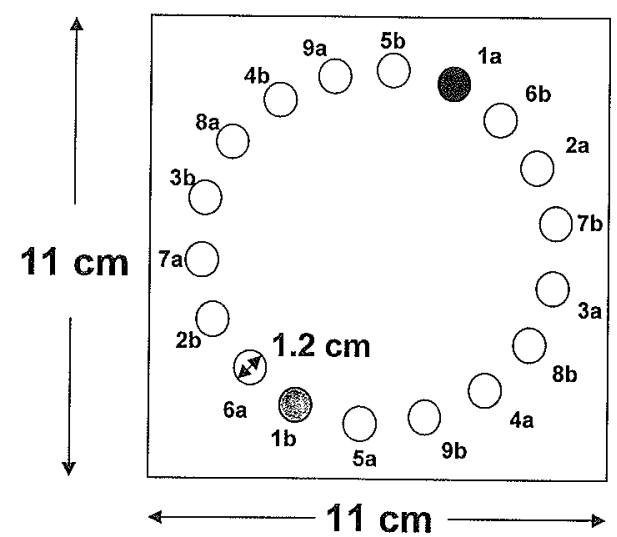

Figure 2. Omnidirectional dragging task and screen dimensions. The numbers next to the circles represent the sequence of the tasks. The letter "a" next to the number indicates that the object is a drag target, the letter " $b$ " indicates that the object is a drag destination, and " $a$ " is dragged to " $b$ ".

the delete key on the keyboard with the mouse-using hand. The target sizes and distances varied slightly depending on the monitor size and screen resolution.

\section{Force measurements during simulated mouse use}

On the 1st day of the study at the beginning, middle, and end of the workday, the subjects were asked to try to simulate the forces that they applied to the sides of the mouse using a nonfunctional Apple ADBII mouse instrumented with a load cell (Pinch Meter; Greenleaf Medical; Palo Alto, CA, USA). They were instructed to hold their real mouse, simulate mouse use, and then switch to the mouse instrumented with the load cell and replicate the force they applied to their regular mouse for a period of 5 seconds. They alternated between the 2 devices until force measurements from 5 simulated mouse pinch force measurements had been collected.

\section{Measuring maximal voluntary contractions}

The maximum forces that a subject could apply to the sides and button of the mouse were measured in the laboratory. An adjustable table and chair were set up to match the table and chair heights of the subject's actual workstation. Then the subject was asked to apply maximal voluntary contractions (MVC) to the sides and button of an Apple ADBII mouse instrumented with load cells (Pinch Meter, Greenleaf Medical, Palo Alto, CA, USA). The MVC applied to the sides and button of the mouse were measured separately and stored on a computer at $50 \mathrm{~Hz}$. The subject was instructed to grip the mouse during the MVC the same way they gripped the mouse during regular use. Three MVC recordings were collected from the sides and button of the mouse. A minimum of 2 minutes elapsed between each MVC. If the 3rd MVC was the highest, additional MVC values were collected until the MVC force declined.

\section{Data analysis and statistical methods}

Regular work. Each hour of mouse force data collected during the subject's regular work was analyzed using a force decomposition program written in Labview 3.1. The program recorded each time the mouse was used (defined as a grip episode) and kept track of idle periods (defined as any period where 0 newtons of force was being registered by both the sides and button of the mouse for 1 second or longer). For each grip episode, the program calculated the mean force, peak force, and grip duration. Summary statistics were calculated across all the grip episodes for each hour of mouse operation, including (i) the mean forces applied to the sides and button of the mouse during use, (ii) mean of the peak forces applied to the sides and button of the mouse, (iii) mean of the grip episode duration, (iv) median of the grip episode duration, (v) mean idle period, (vi) median of the idle period, and (vii) minutes of mouse use during the hour.

To determine whether the forces applied to the mouse varied from hour to hour or between days, a repeatedmeasures analysis of variance (RANOVA) was used, and the $95 \%$ confidence intervals $(95 \% \mathrm{CI})$ were calculated using Bonferroni's method. For an hour of force data to be included in this portion of the analysis, the hour had to contain a minimum of 20 grip episodes ( 26 out of 211 hours of data were excluded). To test for differences between the genders, sign-rank tests were performed, and the $95 \%$ confidence intervals were calculated for the median differences (17).

Sometimes, a certain level of precision is specified, and then data are collected until that level of precision is met in order to determine how long to collect data. In our study we defined precision as the coefficient of variation (standard deviation divided by the mean) divided by the square root of $n$, where $n$ was the number of grip episodes.

To evaluate how long regular work force data would have to be collected to attain a certain level of precision, 
we analyzed the 1st hour of each subject's mouse force data that contained at least 50 grip episodes. With these data, the precision statistic was calculated and iteratively re-calculated with each successive grip episode. Then the average number of grip episodes and the sampling duration needed to reach a $10 \%$ level of precision were determined for (i) the mean forces applied to the sides of the mouse, (ii) the mean forces applied to the button of the mouse, (iii) the peak forces applied to the sides of the mouse, and (iv) the peak forces applied to the button of the mouse.

Standardized tasks. RANOVA methods were also used to determine whether the forces applied to the mouse during the performance of the standardized task battery varied from hour to hour (between the 6 standardized task batteries collected on day 1 ) and between days (days 1 , 2 , and 3 ).

Comparison of simulated mouse use and regular work forces. A RANOVA was used to determine whether there were differences between the forces applied to the sides of the mouse during regular work and simulated mouse use. In addition, a simple linear regression was performed to assess the degree of correlation between the regular work and simulated mouse forces.

Comparison of standardized task and regular work forces. RANOVA methods and Dunnett's follow-up tests were used to determine whether there were differences between the mean forces applied to the mouse during regular work and each of the standardized tasks. With the use of Dunnett's test statistic, the 95\% confidence intervals were calculated for the differences between the means.

To determine whether the standardized task and regular work forces were related, simple linear regressions were performed to assess the degree of correlation (r) between the regular work forces averaged over 3 days (considered the gold standard) and the standardized task forces collected on day 1 . In addition, the performance of various combinations of the standardized tasks were compared with regular work forces by taking the average force for the various standardized task combinations for each subject and correlating them with the regular work forces averaged over 3 days. Since the standardized tasks were collected from each subject 6 times on day 1 (once every hour), the individual values for each subject were based on the median of the 6 measurements in order to obtain a representative correlation. The correlations were calculated when the forces were expressed in newtons and as the percentage of the maximal voluntary contraction (\%MVC). Since there was evidence that the MVC data were not normally distributed, Spearman rank correlations were calculated.
Using the standardized tasks to identify operators who apply higher forces to the mouse. Using the average of the regular work forces applied to the mouse over the 3 days, we categorized each operator as either a "highforce" or "moderate-to-low-force" user. "High-force" users were defined as operators whose forces were in the upper quartile (upper 25\%), whereas "moderate-to-lowforce" users were those whose forces were in the lower 3 quartiles (lower $75 \%$ ). We made this division to split the subjects into 2 groups to match the "diseased" and "nondiseased" paradigm as used in epidemiology. Likewise, the operators were categorized as high-force or moderate-to-low-force users according to their standardized task forces. In order to measure the agreement and validity between the high-force users identified by the regular work and standardized task forces, the kappa coefficient, sensitivity, specificity, and positive predictive values were calculated.

\section{Results}

\section{Regular work}

Based on the averaging of each subject's mouse use over the 3 days, the group mean amount of mouse use per hour was 14.24 (SD 5.70) minutes, accounting for 23.7 (SD $9.5) \%$ of the time the subjects spent working. The mouse was used an average of 78.0 (SD 40.7) times per hour, the average grip episode lasting 12.0 (SD 5.2) seconds. There were no differences between the genders as to how much the mouse was used $95 \% \mathrm{Cl}$ of the difference -15.0 to $7.0 \%, \mathrm{P}=0.37$ ). The median amount of mouse use was 27.5 (range 13.5-40.1)\% of the time for the men and 22.1 (range $6.1-31.9$ ) $\%$ for the women.

The maximal force that the subjects could apply to the sides and button of the mouse during an MVC were 79.5 (SD 21.4) $\mathrm{N}$ and 52.8 (SD 16.8) $\mathrm{N}$, respectively. Three subjects gripped the mouse with their thumb and middle finger and ring and little fingers; 5 subjects used their thumb and ring finger; and 8 subjects used their thumb and ring and little fingers. When the maximal forces were grouped by gender, there were differences between the men and women in the median force applied to the sides $(95.8$ versus $67.6 \mathrm{~N}, 95 \%$ CI $6.6-42.6 \mathrm{~N}$, $\mathrm{P}=0.02)$ and button $(61.1$ versus $46.7 \mathrm{~N}, 95 \% \mathrm{CI}-1.73-$ $32.4 \mathrm{~N}, \mathrm{P}=0.07$ ) of the mouse.

In general, the forces applied to the mouse during regular work were low, with a median force of 0.5 (range $0.3-1.8$ )\%MVC applied to the sides and 0.7 (range $0.4-1.5) \% \mathrm{MVC}$ applied to the button. When the forces applied to the mouse during regular work were expressed in newtons, no differences were observed between the genders (table 1); however, when forces were expressed as the \%MVC, there were small gender differences, the women applying slightly more force. The newton values 
Table 1. Differences between the genders in the mean and peak forces applied to the mouse ( $N=8$ men and $N=8$ women). The $95 \%$ confidence intervals $(95 \% \mathrm{Cl}$ ) and P-values are for the differences between the genders. (\%MVC $=$ percentage of the maximal voluntary contraction)

\begin{tabular}{|c|c|c|c|c|c|c|c|c|}
\hline \multirow[t]{2}{*}{ Mouse } & \multicolumn{4}{|c|}{ Newtons } & \multicolumn{4}{|c|}{$\% M \vee C$} \\
\hline & Median & Range & $95 \% \mathrm{Cl}$ & P-value & Median & Range & $95 \% \mathrm{Cl}$ & P-value \\
\hline \multicolumn{9}{|l|}{ Sides } \\
\hline \multicolumn{9}{|l|}{ Mean } \\
\hline Men & 0.46 & $0.24-0.67$ & \multirow[t]{2}{*}{$-0.11-0.18$} & \multirow[t]{2}{*}{0.54} & 0.5 & $0.3-0.8$ & \multirow{2}{*}{$-0.5-0.1$} & \multirow[t]{2}{*}{0.45} \\
\hline Women & 0.37 & $0.30-0.59$ & & & 0.5 & $0.4-1.8$ & & \\
\hline \multicolumn{9}{|l|}{ Peak } \\
\hline Men & 1.18 & $0.87-1.77$ & \multirow{2}{*}{$-0.29-0.40$} & \multirow[t]{2}{*}{0.71} & 1.3 & $0.9-2.7$ & \multirow{2}{*}{$-1.3-0.2$} & \multirow[t]{2}{*}{0.18} \\
\hline Women & 1.18 & $0.85-1.43$ & & & 1.7 & $1.2-4.3$ & & \\
\hline \multicolumn{9}{|l|}{ Button } \\
\hline \multicolumn{9}{|l|}{ Mean } \\
\hline Men & 0.32 & $0.30-0.44$ & \multirow[t]{2}{*}{$-0.09-0.05$} & \multirow[t]{2}{*}{0.71} & 0.6 & $0.4-1.4$ & \multirow[t]{2}{*}{$-0.5-0.0$} & \multirow[t]{2}{*}{0.06} \\
\hline Women & 0.35 & $0.27-0.45$ & & & 0.8 & $0.6-1.5$ & & \\
\hline \multicolumn{9}{|l|}{ Peak } \\
\hline Men & 1.37 & $1.05-1.71$ & \multirow[t]{2}{*}{$-0.35-0.24$} & \multirow[t]{2}{*}{0.79} & 2.5 & $1.4-5.3$ & \multirow[t]{2}{*}{$-2.1--0.1$} & \multirow[t]{2}{*}{0.04} \\
\hline Women & 1.44 & $1.04-1.76$ & & & 3.0 & $2.5-6.2$ & & \\
\hline
\end{tabular}

Table 2. Comparison between the forces applied to the mouse during regular work and the standardized tasks. The $95 \%$ confidence intervals $(95 \% \mathrm{Cl})$ are for the differences between the regular work and standardized task $(\mathrm{N}=16)$.

\begin{tabular}{|c|c|c|c|c|c|c|}
\hline & \multicolumn{3}{|c|}{ Sides } & \multicolumn{3}{|c|}{ Button } \\
\hline & Mean $(\mathrm{N})$ & SD & $95 \% \mathrm{Cl}$ & Mean (N) & SD & $95 \% \mathrm{Cl}$ \\
\hline \multicolumn{7}{|l|}{ Mean force } \\
\hline Regular work & 0.43 & 0.12 & & 0.35 & 0.06 & \\
\hline Dragging task & 0.79 & 0.37 & $0.24-0.48$ (significant) & 0.90 & 0.25 & $0.44-0.64$ (significant) \\
\hline Pointing task & 0.59 & 0.29 & $0.04-0.28$ (significant) & 0.30 & 0.05 & $-0.04-0.16$ (not significant) \\
\hline Text editing & 0.54 & 0.20 & $0.01-0.24$ (not significant) & 0.63 & 0.12 & $0.18-0.38$ (significant) \\
\hline \multicolumn{7}{|l|}{ Peak force } \\
\hline Regular work & 1.20 & 0.31 & & 1.41 & 0.24 & . \\
\hline Dragging task & 2.14 & 1.28 & $0.47-1.40$ (significant) & 2.51 & 0.86 & $0.79-1.40$ (significant) \\
\hline Pointing task & 1.49 & 0.82 & $-0.18-0.74$ (not significant) & 1.64 & 0.31 & $-0.07-0.55$ (not significant) \\
\hline Text editing & 0.99 & 0.31 & $-0.24--0.68$ (not significant) & 1.50 & 0.28 & $-0.22-0.40$ (not significant) \\
\hline
\end{tabular}

for the forces during regular work are summarized in table 2 .

The RANOVA indicated that there were no differences between hours (figure 3 ) or days (figure 4) in the forces applied to the mouse, nor were there any significant hour-by-day interactions. When the error variance terms from the RANOVA were analyzed, the betweensubject error variances were largest, followed by the between-day error variances, the between-hour error variances being the smallest.

Table 3 shows that, according to the most variable force measure, the mouse would have to be used 42 times for an average of 43.2 minutes to reach a $10 \%$ level of precision for all the force measures.

\section{Standardized tasks}

The RANOVA indicated that the mean forces applied to the sides and button of the mouse during the performance of standardized tasks did not vary between the hours $(\mathrm{P}=0.39$ and $\mathrm{P}=0.91$, respectively) or days $(\mathrm{P}=0.68$ and $\mathrm{P}=0.70$, respectively), nor did the peak forces applied to the sides and button of the mouse vary between the hours ( $\mathrm{P}=0.71$ and $\mathrm{P}=0.84$, respectively) or days $(\mathrm{P}=0.84$ and
$\mathrm{P}=0.89$, respectively). In addition, there were no significant hour-by-day interactions.

\section{Comparison of simulated mouse use and regular work forces}

The RANOVA indicated that there was a difference $(\mathrm{P}$ $<0.01$ ) between the forces applied to the sides of the mouse during regular work $[0.43(\mathrm{SD} 0.13) \mathrm{N}]$ and that measured during simulated mouse use [0.92 (SD 0.35) $\mathrm{N}]$. The correlation between the 2 measures ( $r=0.16$ ) was low. When the forces were expressed as the \%MVC, there was still a significant difference $(0.5$ versus 1.0 $\% \mathrm{MVC}, \mathrm{P}<0.01)$, but an increase in correlation $(\mathrm{r}=0.50)$.

\section{Comparison of standardized tasks and regular work forces}

As table 2 indicates, the forces applied to the mouse during the performance of the standardized tasks were task dependent. There was no one single task for which the standardized task forces matched the forces applied to the mouse during regular work.

Despite the force differences, there were moderateto-strong relationships between the standardized task and regular work forces (table 4). When both side and button 

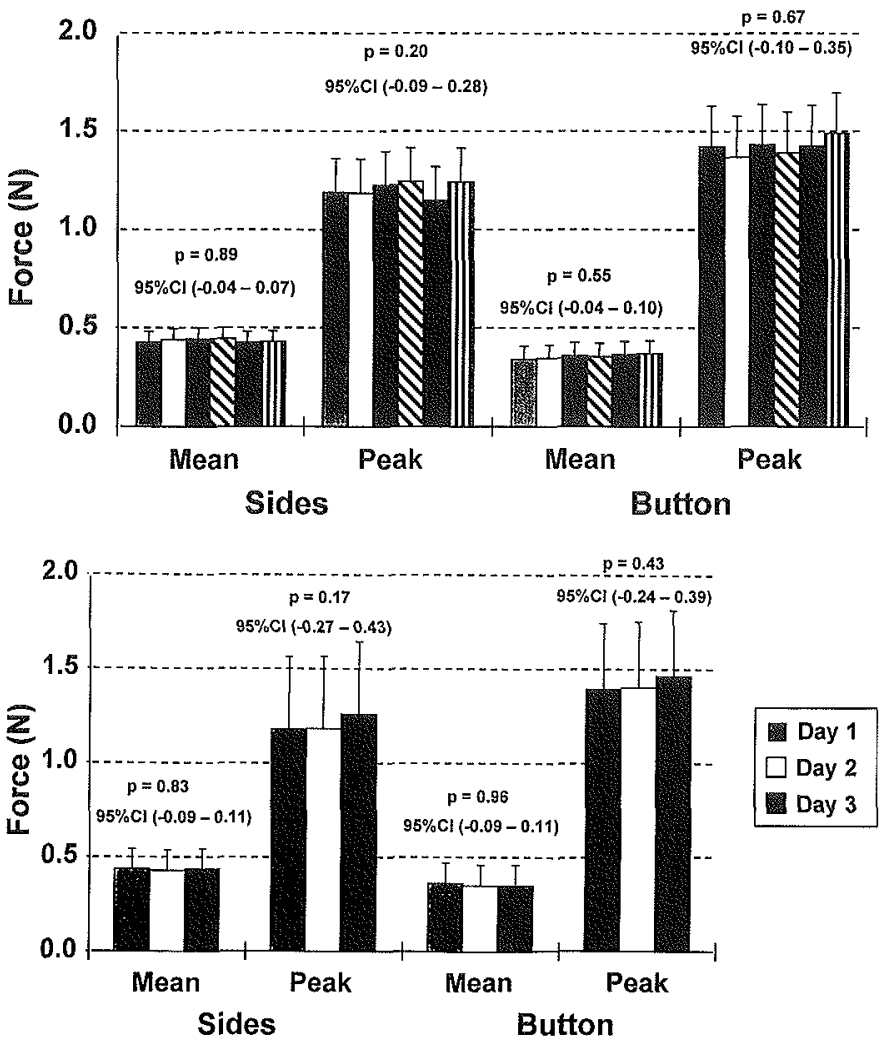

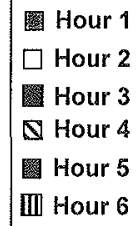

Figure 3. Mean and standard deviation of the forces, grouped by hours, applied to the mouse during regular work on day 1 . The probabilities ( $p$ ) and $95 \%$ confidence interval $(95 \% \mathrm{Cl})$ of the largest differences are shown $(\mathrm{N}=16)$ forces are considered, the text editing task had the best combined overall correlation with regular work forces. When combinations of the standardized tasks were compared with the regular work forces, there were slight increases in the correlation coefficients, the combination of the text editing and pointing test having the best overall correlation. The relationships between regular work and standardized tasks were greater when the forces were expressed as the \%MVC. An increase in the correlation could be explained by an increase in the range of the variables tested when expressed as the \%MVC; however, the increase in the correlation was not due to an increase in range. The ratios between regular work and the standardized task forces were virtually identical when the forces were expressed in newtons and as the \%MVC.

\section{Using the standardized tasks to identify operators who apply higher forces to the mouse}

Table 5 shows the validity of using 2 of the standardized tasks (the text editing and omnidirectional pointing task) as a tool for identifying operators who apply higher forces to the mouse. In general, there was good agreement between the forces that the operators applied to the mouse during regular work and during the performance of the standardized tasks. As indicated by the correlations in table 4 and the agreement measures in table 5 , the power to discriminate between high - and moderate-to-low-force users increased when the forces were expressed as the $\%$ MVC. Although the agreement measured by the kappa
Table 3. Number of grip episodes and time needed to reach $10 \%$ precision in the mouse force measurements when the mouse forces were measured during regular work $(N=16)$.

\begin{tabular}{|c|c|c|c|c|c|c|c|c|}
\hline \multirow[t]{2}{*}{ Mouse } & \multicolumn{4}{|c|}{ Grip episodes (N) } & \multicolumn{4}{|c|}{ Time (min) } \\
\hline & Mean & $\mathrm{SD}$ & Peak & $\mathrm{SD}$ & Mean & SD & Peak & $\mathrm{SD}$ \\
\hline Sides & 17.6 & 17.1 & 27.8 & 18.8 & 20.0 & 23.9 & 31.2 & 34.1 \\
\hline Button & 41.9 & 33.5 & 13.8 & 11.9 & 43.2 & 41.7 & 12.5 & 12.3 \\
\hline
\end{tabular}

Table 4. Correlation between regular work forces and various combinations of the standardized task forces. Correlations are presented when the forces are expressed in newtons and as the percentage of the maximal voluntary contraction $(\% \mathrm{MCV})(\mathrm{N}=16)$.

\begin{tabular}{lccccc}
\hline Task & \multicolumn{2}{c}{ Sides } & & \multicolumn{2}{c}{ Button } \\
\cline { 2 - 3 } & Newtons & $\%$ MVC & & Newtons & $\% M V C$ \\
\hline Dragging & 0.82 & 0.87 & & 0.53 & 0.80 \\
Pointing & 0.80 & 0.89 & & 0.46 & 0.82 \\
Text editing & 0.82 & 0.83 & & 0.73 & 0.92 \\
Dragging \& pointing & 0.85 & 0.91 & & 0.57 & 0.85 \\
Dragging \& text editing & 0.87 & 0.90 & & 0.64 & 0.88 \\
Pointing \& text editing & 0.87 & 0.89 & & 0.73 & 0.94 \\
Text editing, pointing \& dragging & 0.90 & 0.93 & & 0.66 & 0.91 \\
\hline
\end{tabular}

coefficients may not seem high, a kappa coefficient of 0.67 resulted when only 1 out of the 16 subjects was miscategorized. 
Table 5. Measures showing the agreement between the regular work and standardized task forces for identifying operators who applied higher forces to the mouse. Agreement measures are shown when forces are expressed in newtons and as the maximal voluntary contraction (\%MCV) $(\mathrm{N}=16)$. ( $(\kappa=$ kappa, $\mathrm{PPV}=$ ?)

\begin{tabular}{|c|c|c|c|c|c|c|c|c|}
\hline \multirow[t]{2}{*}{ Mouse } & \multicolumn{4}{|c|}{ Newtons } & \multicolumn{4}{|c|}{$\% \mathrm{MVC}$} \\
\hline & $\kappa$ & $\begin{array}{l}\text { Sensi- } \\
\text { tivity }\end{array}$ & $\begin{array}{l}\text { Speci- } \\
\text { ficity }\end{array}$ & PPV & $\kappa$ & $\begin{array}{l}\text { Sensi- } \\
\text { tivity }\end{array}$ & $\begin{array}{l}\text { Speci- } \\
\text { ficity }\end{array}$ & PPV \\
\hline Sides & 0.67 & 0.75 & 0.92 & 0.75 & 0.67 & 0.75 & 0.92 & 0.75 \\
\hline Button & 0.33 & 0.50 & 0.83 & 0.50 & 0.67 & 0.75 & 0.92 & 0.75 \\
\hline
\end{tabular}

\section{Discussion}

This study is the first part of a larger study to determine the role the computer mouse plays in the development of upper-extremity musculoskeletal disorders, and it represents the first time mouse forces have been determined for subjects in their actual offices while performing their actual work. Several key issues related to data collection procedures have been explored, and the results can be used to direct initial data collection procedures in upcoming field studies. First, the forces that the subjects applied to the mouse did not vary between hours or between days. From an exposure assessment standpoint, this finding indicates that the forces that a computer operator applies to the mouse can be characterized in 1 day during any hour of the day. For a $10 \%$ level of precision for the regular force measures of work with a mouse, on the average, the mouse would have to be used 42 times, taking 43.2 minutes to collect. Second, the forces that the subjects applied to the mouse during the performance of standardized tasks differed from the forces applied to the mouse during regular work. However, there were moderate-to-strong correlations between the 2 measures that indicated that standardized task forces may be useful as a relative force exposure measure. If the goal is to discriminate between computer operators or work situations in which "high" compared to "moderate-to-low" forces are applied to the mouse, then a single battery of standardized tasks can be used for identification. A single battery of tasks has the advantage of reducing and simplifying data collection procedures. Finally, the simplest of all collection procedures, having operators simply simulate computer mouse use, did not perform well as an exposure assessment tool.

With respect to characterizing mouse use, the forces applied to the mouse during regular work were low (range $0.3-6.2 \% \mathrm{MVC}$ ), and mouse use accounted for $24 \%$ of the time the subjects spent working. Muscle fatigue has been documented after 5 hours of intensive mouse use (18); however, it is uncertain at this point whether musculoskeletal disorders can result from these low force levels. The correlations between the number of times the mouse was used per hour (work pace) and the force applied to the sides and button of the mouse were low ( $\mathrm{r}$ values $<0.25$ ).

During mouse use, the men and women applied the same absolute (newton) force; however, the relative (\%MVC) force applied by the women was slightly higher. Similar gender differences have been observed in the forces applied to computer keyboards during typing (19). In occupational settings, women have been shown to have a higher prevalence of upper-extremity disorders than men $(3,20-22)$. One possible explanation could be the greater relative (\%MVC) force exposure for women. This possibility stresses the importance of making both absolute and relative force measurements in comparisons evaluating gender differences. If a subject's MVC force is not measured, then relative (\%MVC) force exposure comparisons cannot be made.

A major issue is whether either type of force exposure (absolute or relative) is a better measure of exposure and a predictor of disease and disorder. It is worth noting that with virtually every force measure, the ability of the statistical tests to measure or detect differences was increased when the mouse forces were compared using relative (\%MVC) forces rather than absolute (newtons) forces. The increase in the ability of the statistical tests to detect differences with relative forces was not due to an increase in the range of forces when expressed as the \%MVC. In addition, both mean and peak forces were measured in this study; currently it is uncertain which measure is more important as an exposure measure. However, it is worth noting that there was a strong correlation between the mean and peak forces.

Finally, this study had some limitations. First, the mouse force data were collected from Macintosh mouse users only. It is uncertain if the same findings and trends in mouse use would be observed among personal computer and workstation users. Second, these data were collected from subjects on 1 job site. It would be interesting to collect data from subjects at other job sites and from other occupations. Finally, the patterns and distributions of the mouse force patterns were not characterized in this study. Such a procedure may provide additional information. Despite these limitations, key factors pertaining to computer mouse use and how to collect mouse force exposure data have been identified.

\section{Concluding remarks}

The 3 major findings of this study with respect to exposure assessment research are (i) mouse force measurements should be made while subjects perform their actual work in order to characterize accurately the absolute (newton) forces that subjects apply to the mouse, (ii) the forces applied to the mouse during the performance of a short battery of standardized tasks will work well as a tool for identifying computer operators or work situations 
in which higher forces are applied to the mouse, and (iii) subjects cannot accurately simulate mouse forces.

In the future we hope to collect mouse forces in different occupational settings (eg, different software, hardware, tasks, etc) and use the performance of the standardized task battery to identify computer operators or work situations in which higher forces are applied to the mouse. Ultimately we would like to determine whether the forces that a computer operator applies to the mouse has any predictive value for identifying which computer operators may be at risk for developing mouse-related musculoskeletal disorders.

\section{Acknowledgments}

This research was supported in part by a grant from the John's Hopkins Center for VDT Research and The Swedish Council for Work Life Research.

The authors would like to thank Ron Tal from the Ergonomics Program of the University of California San Francisco, who designed the force-sensing mouse; Brent Duschon, Apple Computer, who assisted with its construction; and Dr Bengt-Olov Wickström, National Institute for Working Life, who assisted with technical issues surrounding the data collection.

\section{References}

1. Franco G, Castelli C, Gatti C. Postural tenosynovitis caused by misuse of a computer input device (mouse). Med Lav 1992;83(4):352-5.

2. Franzblau A, Flaschner D, Albers JW, Blitz S, Werner R, Armstrong T. Medical screening of office workers for upper extremity cumulative trauma disorders. Arch Environ Health 1993;48(3):164-70.

3. Karlqvist L, Hagberg M, Köster M, Wenermark M, Ånell R. Musculoskeletal symptoms among computer-assisted design (CAD) operators and evaluation of self-assessment questionnaire. Int J Occup Environ Health 1996;2,:185-94.

4. Fogleman M, Brogmus G. Computer mouse use and cumulative trauma disorders of the upper extremities. Ergonomics 1995;38(12):2465-75.

5. Armstrong TJ, Martin BJ, Franzblau A, Rempel DM, Johnson PW. Mouse input devices and work-related upper limb disorders: working with display units 94 . Milan (Italy): Elsevier Science, 1995:375-80.

6. Johnson PW, Dropkin J, Hewes J, Rempel D. Office ergonomics: motion analysis of computer mouse usage. In: Proceedings of the American Industrial Hygiene Conference and Exposition. Fairfax (VA): American Industrial Hygiene Association, 1993:12-3.

7. Hanson-Risberg E, Rempel D, Hagberg M, Karlqvist L, Wilgaeus Hjelm E. Inter-method reliability on assessment of duration of visual display terminal work, computer mouse use and working technique. In: Proceedings of the 12th Congress of the International Ergonomics Association. Toronto (ON): International Ergonomics Association, 1994:554-6.

8. Karlqvist L, Hagberg M, Selin K. Variation in upper limb posture and movement during word processing with and without mouse use. Ergonomics 1994;37(7):1261 -7.

9. Johnson PW, Lehman SL, Rempel DM. Measuring muscle fatigue during prolonged computer mouse use. IEEE Engineering in Medicine and Biology Society 18th Amnual International Conference, Amsterdam, Holland. IEEE EMBS. 1996;1256-8.

10. Karlqvist L, Hagberg M, Selin K. Position of the computer mouse - a determinant of posture, muscular load and perceived exertion? In: Proceedings of the 13th Triennial Congress of the International Ergonomics Association, Tampere (Finland). International Ergonomics Association, 1997;4:613.

11. Aarås A, Fostervold KI, Thoresen M, Larsen S. Postural load during VDU work: a comparison between various work postures. Ergonomics 1997;40(11):1125—68.

12. Fernström E, Ericsson MO. Computer mouse or trackpoint effects of muscular load and operator experience. Appl Ergon 1993;28(5;6):347-54.

13. Harvey R, Peper E. Surface electromyography and mouse use position. Ergonomics 1997;40(8):781-78.

14. Karlqvist LK, Bernmark E, Ekenvall L, Hagberg M, Isaksson A, Rostö T. Computer mouse position as a determinant of posture, muscular load and perceived exertion. Scand J Work Environ Health 1998;24(1):62-73.

15. Johnson P, Tal R, Smutz P, Rempel D. Computer mouse designed to measure finger forces during operation. In: Proceedings of the IEEE Engineering in Medicine and Biology Society 15th Annual International Conference. San Diego (CA): IEEE Engineering in Medicine and Biology Society, 1993;1404-5.

16. Johnson PW, Smutz WP, Rempel DM. Fingertip forces measured during computer mouse operation: a comparison of pointing and dragging. In: Proceedings of the 12th Congress of the International Ergonomics Association. Toronto (ON): IEA, 1994;208-10.

17. Campbell M, Gardner MJ. Calculating confidence intervals for some non-parametric analyses. BMJ 1988;296:1454-6.

18. Johnson PW. The development, characterisation and implementation of a technique to measure muscle fatigue during computer use [dissertation]. Berkeley (CA): University of California, 1998.

19. Martin B, Armstrong TJ, Foulke JA, Sivakumaran N, Klinenberg E, Serina E, Rempel D. Keyboard reaction force and finger flexor electromyograms during computer keyboard work. Hum Factors 1996;38:654—64.

20. Bernard B, Sauter S, Fine L, Peterson M, Hales T. Job task and psychosocial risk factors for work-related musculoskeletal disorders among newspaper employees. Scand J Work Environ Health 1994;20:417-26.

21. Grieco A, Occhipinti E, Colombini D. Work postures and musculoskeletal disorders in VDU operators. Boll Ocul 1989;68:99-112.

22. Evans J. Women, men VDU work and health: a questionnaire survey of British VDU operators. Work Stress 1987;1:27183.

23. Davie C, Katifi H, Ridley A, Swash M. "Mouse" - trap or personal computer palsy. Lancet 1991;338:832.

Received for publication: 18 February 1999 